\title{
A expansão dos condomínios fechados: 0 caso de Campos dos Goytacazes, RJ
}

\author{
Viviane Rangel Ribeiro Manhães ${ }^{1}$ \\ Ana Paula Serpa Nogueira de Arruda ${ }^{2}$
}

RESUMO

0 presente artigo analisa a expansão dos condomínios residenciais de alto padrão na cidade de Campos dos Goytacazes, o seu impacto sobre a produção do espaço urbano, a ampliação e ressignificação das áreas periféricas e principalmente as motivações para a moradia nestes espaços. Especialmente no caso dos condomínios horizontais fechados de médio e alto padrão temos a conformação de um processo de "autossegregação", na qual a qualidade de vida e o exclusivismo de classe parecem ser fatores determinantes no momento da escolha de se morar em um condomínio horizontal fechado, aliados ainda à presença de áreas verdes, de lazer e o status social. Cercados por muros, modernos dispositivos de segurança e de distinção de classes, vetores esses utilizados como estratégias de propaganda e venda por grandes e influentes incorporadoras, estes condomínios determinam um novo estilo de vida e normas de convívio entre os iguais, no espaço privado.

PALAVRAS-CHAVE: Condomínios fechados; Espaços públicos; Espaço urbano; Privatização; Segregação.

\section{ABSTRACT}

This article analyzes the expansion of high - quality residential condominiums in the city of Campos dos Goytacazes, its impact on the production of urban space, especially for the extension and re signification of the peripheral areas and the motivations for housing in these spaces. Especially in the case of horizontal condominiums of medium and high standard, we have the conformation of a process of "self-segregation", in which quality of life and class exclusiveness seem to be determining factors when choosing to live in a closed horizontal condominium, allied to the presence of green areas, leisure and social status. Surrounded by walls, modern security devices and class distinctions, these vectors are used as propaganda and sales strategies by large and influential real estate developers, these condos determine a new way of life and living standards among the same people in the private space.

KEY-WORDS: Closed condominiums; Public spaces; Urban space; Privatization; Segregation.

\section{Introdução}

Este artigo tem por objetivo analisar o crescimento dos condomínios horizontais fechados, sobretudo os de alto padrão, nas cidades médias, em especial na cidade de Campos dos Goytacazes, que parecem constituir uma nova e notável forma de segregação e fragmentação sócio-espacial. Para este fim, tentaremos compreender as principais motivações que levaram parte da população - classe média e alta - a optarem por morar em condomínios horizontais fechados nesta cidade, o que explica em muito a expansão e apelo mercadológico deste tipo de moradia.

A cidade de Campos dos Goytacazes, localizada na região norte fluminense, parece ser um exemplo emblemático da problemática que constitui este artigo ao possuir - espalhados em sua malha urbana - condomínios residenciais de diversos tipos: empreendimentos

\footnotetext{
1 Mestre do Programa de Pós-graduação em Planejamento Regional e Gestão de Cidades, Universidade Candido Mendes - Campos dos Goytacazes/RJ, Brasil. vivianerribeiro@gmail.com

2 Professora do Programa de Pós-graduação em Planejamento Regional e Gestão de Cidades, Universidade Candido Mendes - Campos dos Goytacazes/RJ, Brasil. serpanogueira@gmail.com
} 
voltados para a classe alta, que se destacam pela diferenciação e exclusivismo; residenciais voltados para classes médias baixa, grande parte empreendidos por construtoras nacionais (Tenda, MRV, PDG entre outras); e condomínios de habitação popular, edificados pelo poder público, como os do Morar Feliz, por exemplo. Esta configuração determina a existência de mecanismos que impedem determinados atores sociais de participarem da vida urbana em sua plenitude, o que acaba por representar sérios danos ao exercício da cidadania e à apropriação da cidade (ARRUDA, 2014).

Especialmente no caso dos condomínios horizontais fechados de médio e alto padrão temos a conformação de um processo de "autosegregação", na qual a qualidade de vida e o exclusivismo de classe parecem ser fatores determinantes no momento da escolha de se morar em um condomínio horizontal fechado, aliados ainda à presença de áreas verdes, de lazer e o status social. Neste contexto, o modelo de uma cidade composta por muros - "verdadeiros enclaves" nas palavras de Caldeira (2000), que comprometem a mobilidade urbana e estimulam a segregação social - deve ser motivo de preocupação da sociedade.

Estes enclaves fortificados representam uma nova forma de moradia para as classes de maior poder econômico, conferindo qualidade de vida, exclusivismo de classe no qual leva o morador a ter status social, gerando um processo que conflui em distâncias sociais, ratificando as diferenças e desigualdades sociais entre as classes. Ao analisarmos as propagandas imobiliárias podemos observar o estilo de vida que é criado para classe média e alta e os elementos que constituem os padrões de diferenciação social em vigor na sociedade atual.

Além disso, no caso de Campos dos Goytacazes, o poder público tem sido pouco atuante nos últimos anos frente à expansão dos condomínios horizontais fechados. Certamente porque pesa o fator da obtenção de receitas como, por exemplo, o IPTU, quando da transformação de áreas rurais em urbanas - caso específico da cidade com a utilização de antigas áreas de usinas sucroalcooleiras para a edificação destes condomínios. Desta forma, a malha urbana da cidade foi intensamente modificada para suportar a implantação desses empreendimentos.

A metodologia utilizada contou com a realização de entrevistas com moradores de condomínios privados de alto padrão, na expectativa de entendimento das motivações que os levaram a optar por estes espaços. Para fins de organização, este artigo está dividido em mais três seções, além desta introdução: no item dois será tratada, brevemente, uma discussão sobre o crescimento dos condomínios horizontais fechados e a fragmentação socioespacial consequente deste processo. No item três será apresentado a cidade de Campos dos Goytacazes, com ênfase no processo de expansão dos condomínios fechados. No item quatro apresentaremos os dados provenientes de nosso estudo de caso, realizado por meio de entrevistas com moradores de um condomínios residencial de alto padrão, a fim de entender os motivos que levam a expansão desta modalidade de moradia e os ensejos de seus moradores. Finalmente no item 5 , apresentaremos as considerações finais.

\section{Condomínios horizontais fechados e a fragmentação socioespacial}

Em muitas cidades, como em Campos dos Goytacazes, a segregação vem ganhando novos formatos e o mesmo espaço abriga grupos sociais muito diferentes. Mesmo que a distância entre esses grupos seja atenuada, não significa que haja menos segregação; pelo contrário, a segregação é aumentada, em muito, pela fragmentação social e pelas disparidades socioespaciais (SANTOS, 2013; ARRUDA, 2014), "pois embora a distância física entre imóveis luxuosos e ocupações/favelas esteja cada vez menor, a distância social se aprofunda com os muros (materiais e imateriais)" (SANTOS, 2013, p. 53). Podemos observar 
nitidamente essa ocorrência na cidade de Campos, onde alguns dos mais luxuosos condomínios horizontais fechados foram construídos ao lado de favelas, como é o caso, por exemplo, do Condomínio Residencial Athenas construído ao lado da favela da Linha e o do Condomínio Bougainville construído ao lado da favela do Matadouro.

Nos séculos XIX e início do XX, a urbanização das cidades brasileiras seguiu modelos europeus. Em 1840, as cidades europeias sofreram influências das reformas urbanas feitas por Haussmann em Paris. (FISHMAN, 2002, apud D'OTTAVIANO, 2008). Na Inglaterra, no final do século XVIII, surgem os primeiros subúrbios. De acordo com D’Ottaviano (2008, p. 37), o surgimento do subúrbio "significou uma importante transformação na cidade que até então possuía valores urbanos vigentes tais como: centro e periferia, separação dos locais de trabalho e moradia", criando novas formas de espaço urbano. A partir de 1920, ocorre uma mudança para o modelo norte-americano, com a expansão das áreas periféricas e o crescimento do uso de automóveis.

Até então eram nos subúrbios que moravam as pessoas mais pobres e agora esse local passa a ser moradia das pessoas com maior poder aquisitivo. As atividades industriais e o grande comércio também foram excluídos dessas áreas. Segundo Fishman (2002, p. 25 apud D'OTTAVIANO, 2008, p. 38), "o subúrbio deveria possuir características construtivas e de desenho urbano que o diferenciassem tanto da cidade quanto do campo".

Os subúrbios foram estabelecidos aos arredores das cidades - franjas - onde geralmente as terras eram baratas e era fácil acessá-las por carruagens. Logo depois, essas terras foram transformadas em áreas urbanas com grande valor de mercado. Surgia um novo estilo de morar, um novo estilo de vida. Essas novas áreas eram um ótimo investimento para aqueles que possuíam um poder econômico mais elevado. Vale ressaltar, que essas terras, que antes eram acessadas por carruagens, abriram caminho para o crescimento e consolidação do automóvel. Nos dias atuais, os condomínios horizontais fechados também se encontram em áreas periféricas das cidades, no entanto o acesso a essas áreas é facilitado pela ampliação e construção de novas vias e pelo uso frequente do automóvel (D'Ottaviano, 2008).

No caso americano, há uma característica diferente das outras cidades, o uso intensivo da propaganda, no qual se vende o ideal norte-americano de habitação. De acordo com a D’Ottaviano (2008, p. 44), "os subúrbios passam então a serem zonas residenciais valorizadas, onde pessoas com alto poder aquisitivo escolhem viver em "bairros-jardim", caracterizados pela segregação de classes e por moradias isoladas".

A mesma autora ainda observa que, o "discurso do medo e da segurança não esteve ligado à formação de bairros residenciais homogêneos nos Estados Unidos, mas sim a uma cultura, desenvolvida ao longo do final do século XIX e do século XX" (D'OTTAVIANO, 2008, p. 51).

Neste contexto, Ribeiro (1997) aponta que a globalização tem contribuído para transformações ocorridas no espaço das cidades. Como consequência, surgem bairros exclusivos para a camada superior enquanto a classe inferior é deslocada para outros bairros, geralmente, para áreas periféricas.

No caso brasileiro, observamos na década de 1980 o boom da construção civil em todo território, e a expansão dos condomínios horizontais fechados em várias cidades brasileiras. Estes empreendimentos causaram impactos significativos na estrutura urbana das cidades, apontando para novos vetores de expansão.

Como forma de exemplificação, na cidade de Campos dos Goytacazes, de 1980 até 2014, vem crescendo o número de condomínios horizontais fechados com características bastante diversas: vão desde pequenos condomínios com até 14 casas unifamiliares, até grandes glebas com mais de 500 lotes residenciais. Essas últimas são entendidas como urbanizações fechadas, verdadeiros enclaves fortificados, para segmentos de média à 
alta classe, possuindo uma relativa autonomia com relação aos serviços oferecidos pela cidade. Todos esses empreendimentos são murados e muitos desses condomínios já possuem em seu interior serviços de comércio para atender aos moradores de dentro do condomínio. Ampliando a escala de observação, vários condomínios fechados localizados nas grandes metrópoles já oferecem aos seus moradores serviços de escola, shopping centers, comércio, trabalho e lazer em um mesmo lugar: dentro dos condomínios. Ou seja, os moradores não precisam nem acessar a cidade para poder usufruir de seus serviços.

Outra questão que chama atenção são os investimentos em infraestrutura quando comparado os investimentos privados que são feitos dentro dos condomínios. Os condomínios horizontais fechados promovem a privatização dos serviços públicos no sentido de que quando se trata de investimentos públicos em infraestrutura estes são bastante acanhados quando relacionados aos investimentos privados que são feitos nas áreas internas dos condomínios horizontais fechados.

Podemos observar também, na cidade de Campos dos Goytacazes, que esses novos empreendimentos estão sendo implantados em áreas que eram rurais e foram transformadas em urbanas, alterando a morfologia da cidade. De acordo com Sabatini, 2004:

A construção de condomínios horizontais fechados para classes médias e altas fora das áreas tradicionais de concentração dessas classes é talvez a mais notória e extensa alteração na estrutura interna das cidades. (...) Cercas eletrificadas e guardas armados são formas violentas de privatização do espaço público que contrastam com o entorno imediato, especialmente quando a vizinhança é pobre (...). Rodovias e anéis rodoviários novos e renovados têm alterado a condição de acessibilidade das cidades, permitindo gerar extensas áreas de mercado e, consequentemente, permitindo certa dispersão desses mega-projetos. (SABATINI et al., 2004, p. 69)

De acordo com estudos realizados por Sabatini (2004), os condomínios horizontais fechados têm um papel fundamental na consolidação de um novo padrão de segregação residencial, ou seja, da passagem do padrão centro periferia para um padrão fractal ${ }^{3}$. Assim podemos observar que, no século XX havia uma concentração da classe alta no centro e que com as mudanças econômicas ocorridas em 1980 e a expansão do setor imobiliário, essa classe se dispersa para as áreas periféricas, principalmente, por conta dos inúmeros lançamentos de condomínios fechados nas áreas afastadas das cidades.

Estudando o caso de Campos dos Goytacazes, podemos identificar que alguns espaços são fragmentados em parte ou simplesmente não se conectam mais, que é caso dos condomínios horizontais fechados e os lugares onde estão inseridos na cidade. Eles formam enormes paredões que fracionam ruas, avenidas e às vezes bairros inteiros, prejudicando a mobilidade e a convivência entre as pessoas.

Assim, com base na literatura existente, podemos concluir que esses novos empreendimentos - os condomínios horizontais fechados - possuem as seguintes características: ocupam enormes áreas, geralmente localizados em áreas periféricas das cidades, oferecem áreas de lazer e proximidade com a natureza, privatização de espaços públicos, o que traz um

3 Na primeira metade do século XXI, podemos observar uma reorganização espacial das cidades em escalas diferentes, com o surgimento de uma urbanização mais espraiada, fragmentada e desconexa. Apesar das novas formas urbanas (fragmentadas, dispersas, extensivas, difusas, reticulares, fractais), a redefinição do conceito de centro-periferia é importante para entendermos o fenômeno urbano na atualidade, principalmente quando falamos de cidades capitalistas onde o capital tende a se concentrar, reproduzindo desigualdades em escalas cada vez maiores. "Um ponto importante diz respeito ao fato de que a fractalização torna a periferia mais dispersa e fragmentada sobre o espaço metropolitano. Pode-se falar em um contínuo esgarçamento do tecido urbano sobre as áreas periféricas, o que faz com que a cidade se estenda sobre o território de uma forma diferente do que o observado até então. A fractalização do urbano não acaba com a noção de centro e periferia, mas essa dimensão se estabelece num nível diferente do anterior: centro e periferia se realizam por intermédio da fractalização". (CANETTIERI, 2015, p. 25-39). 
sentimento de exclusividade e status social, e a separação com o mundo lá fora, com a diversidade social e cultural, tendo como figura principal a utilização dos muros e dos sistemas modernos de segurança.

\section{Os condomínios horizontais fechados em Campos dos Goytacazes}

Por ser o maior município das Regiões Norte e Noroeste Fluminense, Campos dos Goytacazes ocupa um papel de grande relevância para o desenvolvimento do interior do estado do Rio de Janeiro. Foi uma importante cidade no setor sucroalcooleiro até o final da década de 1980 e depois no setor petrolífero, que sustenta não só a condição de vida de diversos munícipes, mas também a administração pública municipal que, por sua vez, recebe uma arrecadação vultosa dos chamados royalties ${ }^{4}$ e participação especial ${ }^{5}$ da exploração do petróleo da chamada Bacia de Campos.

O crescimento do mercado imobiliário em Campos dos Goytacazes viveu um grande boom nos últimos anos, principalmente nos anos 2000, impulsionado principalmente pela economia do petróleo, com as novas descobertas do pré-sal e a instalação do complexo logístico do Porto do Açu. Somente nos anos 2000, tivemos em Campos dos Goytacazes o lançamento de 17 empreendimentos da tipologia de condomínio horizontal fechado.

Apesar de vivermos atualmente em um período de crise econômica no Brasil, muitos empreendimentos residenciais, - de classe média e alto padrão - lançados nos últimos anos, ainda se encontram em fase de obras, mostrando que pelo menos para este padrão de empreendimento ainda são feitos investimentos.

De acordo com o levantamento realizado neste artigo, Campos dos Goytacazes possui 32 condomínios horizontais fechados de alto padrão, no período compreendido entre 1981 a 2014, com um total de mais de 5.154 lotes, chamando atenção à concentração deles em determinadas ruas ou avenidas e o tamanho das áreas para os novos empreendimentos, conforme demonstra a Tabela 01 e a Figura 01:

TABELA 01: Relação de condomínios horizontais fechados, Campos dos Goytacazes-RJ

\begin{tabular}{|l|c|l|c|c|c|c|}
\hline \multicolumn{1}{|c|}{ CONDOMÍNIO } & ANO & \multicolumn{1}{|c|}{ LOCALIZAÇÃO } & Á. TOTAL & $\begin{array}{c}\text { N }^{\circ} \\
\text { LOTES }\end{array}$ & $\begin{array}{c}\text { Á. TOTAL } \\
\text { DE LOTES }\end{array}$ & $\begin{array}{c}\text { Á. VERDE I } \\
\text { LAZER }\end{array}$ \\
\hline Itacoatiara & 1981 & Av. Alberto Lamego & $23.691,10$ & 80 & $13.545,00$ & $2.646,65$ \\
\hline Bosque das Acácias & 1986 & Av. Alberto Lamego & $45.534,00$ & 89 & $29.548,60$ & ND \\
\hline Bougainvillee & 1987 & Av. Alberto Lamego & $93.090,92$ & 151 & $62.721,89$ & $8.233,00$ \\
\hline Green Peace & 1988 & R. dos Goitacazes & $7.458,00$ & 14 & $5.928,85$ & 0 \\
\hline Village dos Goytacazes & 1990 & R. dos Goitacazes & $56.128,00$ & 94 & $36.712,54$ & $6.265,91$ \\
\hline Villa Alice & 1993 & $\begin{array}{l}\text { Av. Sen. José Carlos } \\
\text { Pereira Pinto }\end{array}$ & $33.366,52$ & 46 & ND & $9.484,89$ \\
\hline Castanheiras & 1995 & Av. Pres.Vargas & ND & 125 & $35.845,25$ & $4.582,80$ \\
\hline
\end{tabular}

4 Os royalties são a compensação financeira, além da tributação regular, relativo à extração de recursos minerais não renováveis, tendo o objetivo de garantir o caráter intergeracional da tributação, garantindo que os recursos oriundos de tais atividades continuem beneficiando as futuras gerações mesmo após o esgotamento da atividade em si. (Klintowitz, 2016).

5 Participações Especiais é a tributação exclusiva do setor de petróleo que consiste na tributação adicional sobre aqueles poços que atingem níveis excepcionais de produção. (Klintowitz, 2016). 


\begin{tabular}{|c|c|c|c|c|c|c|}
\hline CONDOMÍNIO & ANO & LOCALIZAÇÃO & Á. TOTAL & $\begin{array}{c}\mathbf{N}^{\circ} \\
\text { LOTES }\end{array}$ & $\begin{array}{l}\text { Á. TOTAL } \\
\text { DE LOTES }\end{array}$ & $\begin{array}{l}\text { Á. VERDE I } \\
\text { LAZER }\end{array}$ \\
\hline Golden Garden & 1995 & Av. Nilo Peçanha & $89.336,95$ & 124 & $59.146,74$ & $12.704,37$ \\
\hline Village Saint Germain & 1995 & Av. Pres.Vargas & ND & 117 & ND & $4.360,50$ \\
\hline Parque das Palmeiras & 1997 & Av. Nilo Peçanha & $8.968,06$ & 15 & $6.845,37$ & 665,95 \\
\hline Res. Hibiscus & 1998 & Av. Pres.Kennedy & $23.443,33$ & 71 & $14.734,00$ & $3.690,24$ \\
\hline Parque das Palmeiras II & 2001 & Av. Nilo Peçanha & $12.252,60$ & 18 & $8.306,00$ & $1.670,00$ \\
\hline Sonho Dourado & 2001 & Av. Nilo Peçanha & $140.489,00$ & 227 & $85.750,25$ & $13.542,00$ \\
\hline Remanso do Parayba & 2003 & Rod. BR 356 & $96.291,02$ & 58 & $85.921,39$ & $10.369,63$ \\
\hline Palm Springs & 2004 & Rod. BR 356 & $98.736,00$ & 93 & $58.568,16$ & $49.070,25$ \\
\hline Privilége & 2004 & Av. Alberto Lamego & $178.584,77$ & 211 & $109.004,62$ & $28.752,49$ \\
\hline Da Torre & 2005 & Av. Nilo Peçanha & $15.946,00$ & 20 & $10.729,65$ & $2.697,92$ \\
\hline Granja Corrientes & 2005 & Av. Pres. Vargas & $165.778,15$ & 182 & $103.617,03$ & $31.456,87$ \\
\hline Athenas Park & 2007 & R. Aires de Souza & $274.713,51$ & 244 & $146.400,00$ & $85.455,00$ \\
\hline Vale do Paraíba & 2007 & Rod. BR 356 & $146.684,55$ & 151 & $84.329,48$ & $23.262,88$ \\
\hline Terra Nova & 2008 & Estrada Santa Rosa & $136.637,47$ & 468 & $66.057,23$ & $29.227,66$ \\
\hline Canto do Bosque & 2010 & R. Victor J. Aguiar & $13.828,90$ & 18 & $9.611,70$ & $1.922,34$ \\
\hline Parthenon Park & 2010 & R. Aires de Souza & $308.734,64$ & 434 & $186.259,93$ & $34.583,62$ \\
\hline Damha I & 2013 & R. Aires de Souza & $349.275,96$ & 446 & $185.805,73$ & $74.826,57$ \\
\hline Royal Boulevard & 2013 & R. Aires de Souza & $450.562,79$ & 525 & $253.346,44$ & $94.302,79$ \\
\hline Vivere & 2013 & Av. José Alves Azevedo & $12.097,35$ & 53 & $8.618,54$ & 773,22 \\
\hline Alphaville & 2014 & Av. Lourival M. Beda & $443.482,00$ & 592 & $265.230,30$ & $48.410,65$ \\
\hline Damha II & 2014 & R. Aires de Souza & $394.232,96$ & 488 & $209.304,20$ & $72.956,27$ \\
\hline
\end{tabular}

Fonte: Dados obtidos no setor de arquivo da Secretaria Municipal de Obras e Urbanismo da Prefeitura de Campos dos Goytacazes, por Viviane Rangel Ribeiro Manhães

\section{Observações:}

1. Dados obtidos no setor de arquivo da Secretaria Municipal de Obras e Urbanismo da Prefeitura de Campos dos Goytacazes;

2. ND = Dados não disponíveis para consulta;

3. Os condomínios Nashville Park(a), Raul Linhares(b), Solar dos Airizes(c) e Verti Vita (d) não estão listados na tabela devido aos seguintes motivos:

a. Considerado como área rural. Informações não disponíveis;

b. Dados não existentes na Secretaria de Obras e Urbanismo;

c. Empreendimento em fase de divulgação e aprovação;

d. Dados não encontrados na Secretaria de Obras e Urbanismo. 


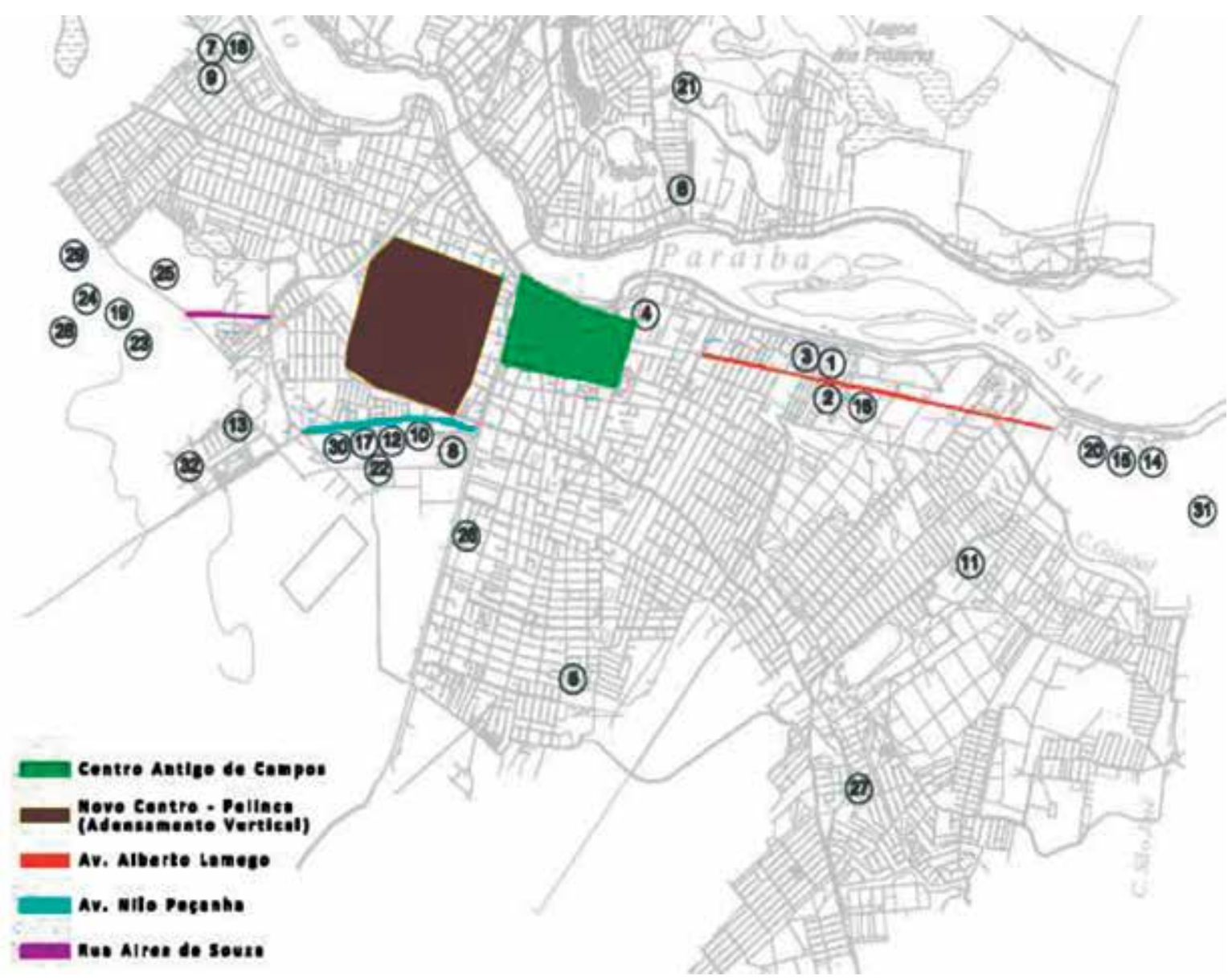

Fonte: Mapa obtido no setor de arquivo da Secretaria Municipal de Obras e Urbanismo da Prefeitura de Campos dos

Goytacazes, adaptado por Viviane Rangel Ribeiro Manhães

1 - Itacoatiara (Horto)

2 - Bosque das Acácias

3 - Bougainvillee

4 - Green Peace

5 - Village dos Goytacazes

6 - Villa Alice

7 - Castanheiras

8 - Golden Garden

9 - Village Saint Germain

10 - Parque das Palmeiras

11 - Residencial Hibiscus

12 - Parque das Palmeiras II
13 - Sonho Dourado
14 - Remanso do Parayba
15 - Palm Springs
16 - Privilége
17 - Da Torre
18 - Granja Corrientes
19 - Athenas Park
20 - Vale do Paraíba
21 - Terra Nova
22 - Canto do Bosque

23 - Parthenon Park

24 - Damha I

25 - Royal Boulevard

26 - Vivere

27 - Alphaville

28 - Damha II

29 - Nashville Park

30 - Raul Linhares

31 - Solar dos Airizes

32 - Verti Vita

Conforme podemos observar, nos anos 1980 houve uma concentração de condomínios na Avenida Alberto Lamego, local que à época era considerado deserto e pouco habitado, hoje está localizado nessa Avenida a Universidade Estadual do Norte Fluminense-UENF, implantada ali desde 1991, a UENF é a mais importante instituição pública do interior do estado, possui conceituados programas de pós-graduação o que atrai estudantes de todas as regiões do Brasil, e que obviamente, pretendem morar próximo a ela, com isso essa Avenida passou a concentrar um conjunto de equipamentos como bares, restaurantes, supermercados, academias de ginástica e os mais diversos tipos de estabelecimentos comerciais. 
Nos anos 1990, a Avenida Nilo Peçanha passa a atrair os principais investimentos. Hoje nessa avenida está instalado um supermercado da rede mundial Walmart assim como a maior e mais bem equipada academia de ginástica da cidade e outros empreendimentos.

A partir de 2007, a Rua Aires de Souza passa a ser o foco dos empreendimentos, também conhecida como Estrada das Palmeiras, no Parque Rodoviário, onde existem aproximadamente oito condomínios fechados: uns já concluídos e ocupados e outros ainda na fase de implantação. A Rua Aires de Souza margeia a lateral do Shopping Boulevard (o primeiro shopping de grande porte implantado na cidade em abril de 2011) e constitui-se como principal via de acesso a tais condomínios, sendo praticamente fechada, não ligando a área a outros bairros, como por exemplo, o Parque Esplanada e o Parque Julião Nogueira, separados apenas pelo Canal do Saco.

Ao mesmo tempo, neste mesmo local, vem sendo realizada a remoção de moradores da favela Margem da Linha, sendo os mesmos transferidos para conjunto popular Morar Feliz. Este conjunto foi construído pela prefeitura, e estudos demonstraram inúmeros problemas sociais, econômicos e de segurança decorrentes de sua implementação (ARRUDA, 2014).

Desta forma, também no caso de Campos dos Goytacazes, - tal qual em diversas cidades brasileiras - não assusta a proximidade de alguns residenciais privados com áreas de favelas, formando verdadeiros "enclaves fortificados". Esses empreendimentos possuem um sofisticado sistema de segurança, encontram-se murados, com porteiros, guaritas, e cercas eletrificadas, seguros e protegidos daqueles que, embora haja proximidade geográfica, mantêm-se a distância social.

Neste contexto, observa-se, nos últimos anos, a chegada à cidade de empreendedoras "urbanizadoras" para camadas de médio e alto poder aquisitivo, tais como "Alphaville" e "Damha", além de construtoras nacionais de empreendimentos de classe média, tais como "ARCO", "MRV" e "TENDA". Em contrapartida, há a iniciativa municipal, constituída pelo programa habitacional Morar Feliz, em favor das camadas populares, "socialmente vulneráveis", fazendo da gestão municipal um importante agente modelador do território urbano, reforçando, em última análise, as áreas periféricas. Assim como, passiva ao pouco regular a edificação destes condomínios horizontais, o que acaba por acentuar a fragmentação urbana existente em Campos (ARRUDA, 2014).

Como podemos observar na Figura 02, a localização desses condomínios é estrategicamente pensada no sentido de promover a expansão da malha urbana e a valorização e especulação imobiliária.

FIGURA 02: Localização dos condomínios horizontais fechados em Campos dos Goytacazes-RJ: Expansão em Áreas Periféricas

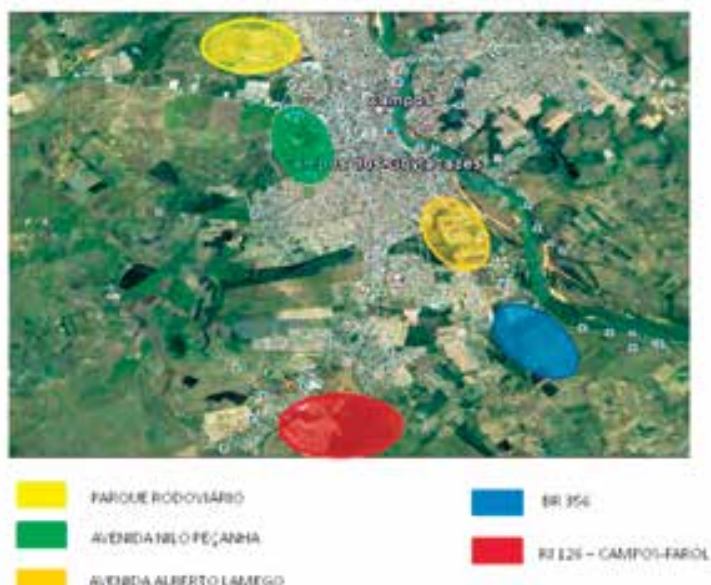


Os empreendimentos geralmente usam como atrativos os serviços que serão ofertados tanto internamente, dentro dos condomínios, quanto às facilidades do entorno onde esses empreendimentos estarão localizados. Outro aspecto relevante é o aumento do número de condomínios horizontais fechados cada vez maiores, diante da grande quantidade de oferta de terras que eram rurais e se transformaram em urbanas, acarretando uma maior segregação socioespacial na cidade. Por muitas vezes, temos a fragmentação de bairros inteiros por conta do tamanho desses condomínios, por serem construídos lado a lado e murados. Temos ainda a reconfiguração da periferia da cidade, com o surgimento de novas centralidades, ofertas de serviços e pela expansão da periferia por meio dos conjuntos residenciais privados.

\section{Condomínios residenciais de alto padrão: motivações para a moradia nestes espaços}

Espaços residenciais fechados, chamados condomínios, representam uma tipologia habitacional em expansão em todo mundo. Um dos maiores motivos, descrito na literatura, que fomenta essa expansão é a questão da segurança nas cidades. Contudo, nos últimos anos, outros fatores têm sido relatados na literatura (Andrade, 2002; Melgaço, 2012) como a busca pela qualidade de vida, o exclusivismo de classe, aliados ainda à presença de espaços verdes e de lazer, proporcionando status social. O objetivo deste item é compreender e identificar se nos dias atuais existem - também no caso de Campos dos Goytacazes outras premissas que permeiam esse tipo de moradia, assim como as razões que levam uma grande parcela da população, média e alta, a optarem em morar em condomínios horizontais fechados.

A pesquisa foi desenvolvida no Condomínio Residencial Athenas Park, na cidade de Campos dos Goytacazes, tendo a princípio uma questão instigante: quais motivos levaram uma grande parcela de determinada classe profissional e social a escolher morar no condomínio Athenas. Assim, a pesquisa foi desenvolvida com os moradores do condomínio por meio de entrevistas semi-estruturadas. O condomínio estudado conta com lotes de 20x30m, ruas largas e arborizadas, e com uma extensa área verde e de lazer, possuindo um grande lago, cercado por animais, pomar, praças, playground, academia, pistas de caminhada, quiosques e quadras, perfazendo um total de $85.455,00 \mathrm{~m}^{2}$ de área verde e de lazer.

A análise das respostas das entrevistas realizadas permitiu o delineamento das expectativas dos moradores do condomínio estudado, ao se mudarem para o mesmo, em aspectos como qualidade de vida (áreas verdes e de lazer) e exclusivismo de classe (relações de vizinhanças e status social). A questão da segurança não foi mencionada pelos moradores do condomínio analisado como um fator determinante para a mudança a não ser quando perguntada sobre ela.

Nesse contexto, a segurança também não é mais um elemento primordial exclusivo para se morar em condomínios, outros elementos parecem definir um novo conceito de exclusividade como a busca por lugares próximos a natureza, o contato com o verde, com o lazer, com animais, com elementos que se relacionam a uma "ruralidade". Essa aspiração por ares bucólicos, pela busca por uma ruralidade no urbano, parece ser a "qualidade" de vida desejada pelas classes média e alta apontadas nessa pesquisa.

O condomínio estudado está localizado no Parque Rodoviário, em uma área periférica da cidade de Campos dos Goytacazes, em terras que pertenciam a Fazenda do Saco, nas quais eram utilizadas para o plantio de cana de açúcar. Este condomínio foi escolhido por ser bem representativo deste processo que parece estar em expansão na cidade: a utilização de amplas áreas provenientes de usinas $(\mathrm{ZACHI}, 2012)$ para edificação de condomínios privados de alto padrão que apelam para um conceito mercadológico de grandes áreas 
verdes e de lazer, e pela exclusividade residencial. Com a transformação dessa área rural em urbana, e como elas se localizavam bem próximas a uma importante via de acesso, a BR 101, foi feito o desmembramento das terras da fazenda, e juntamente com os interesses dos setores privado e imobiliário, foi realizado o lançamento de vários condomínios horizontais fechados no bairro.

Neste bairro está localizada a Favela Margem da Linha, uma área que nos últimos anos tem sofrido constantes tentativas de reassentamento por parte da prefeitura de Campos dos Goytacazes. Em verdade, parte das famílias do local já foi removida para conjuntos habitacionais do Morar Feliz, um programa municipal. Outra parte resiste à remoção, alegando que a mesma é fruto da especulação imobiliária pela qual o local vem passando em virtude da expansão habitacional do mesmo e da localização do Shopping Boulevard.

A Figura 03 deixa bem clara a localização do Parque Rodoviário em área periférica da cidade.

FIGURA 03: Foto aérea do Parque Rodoviário

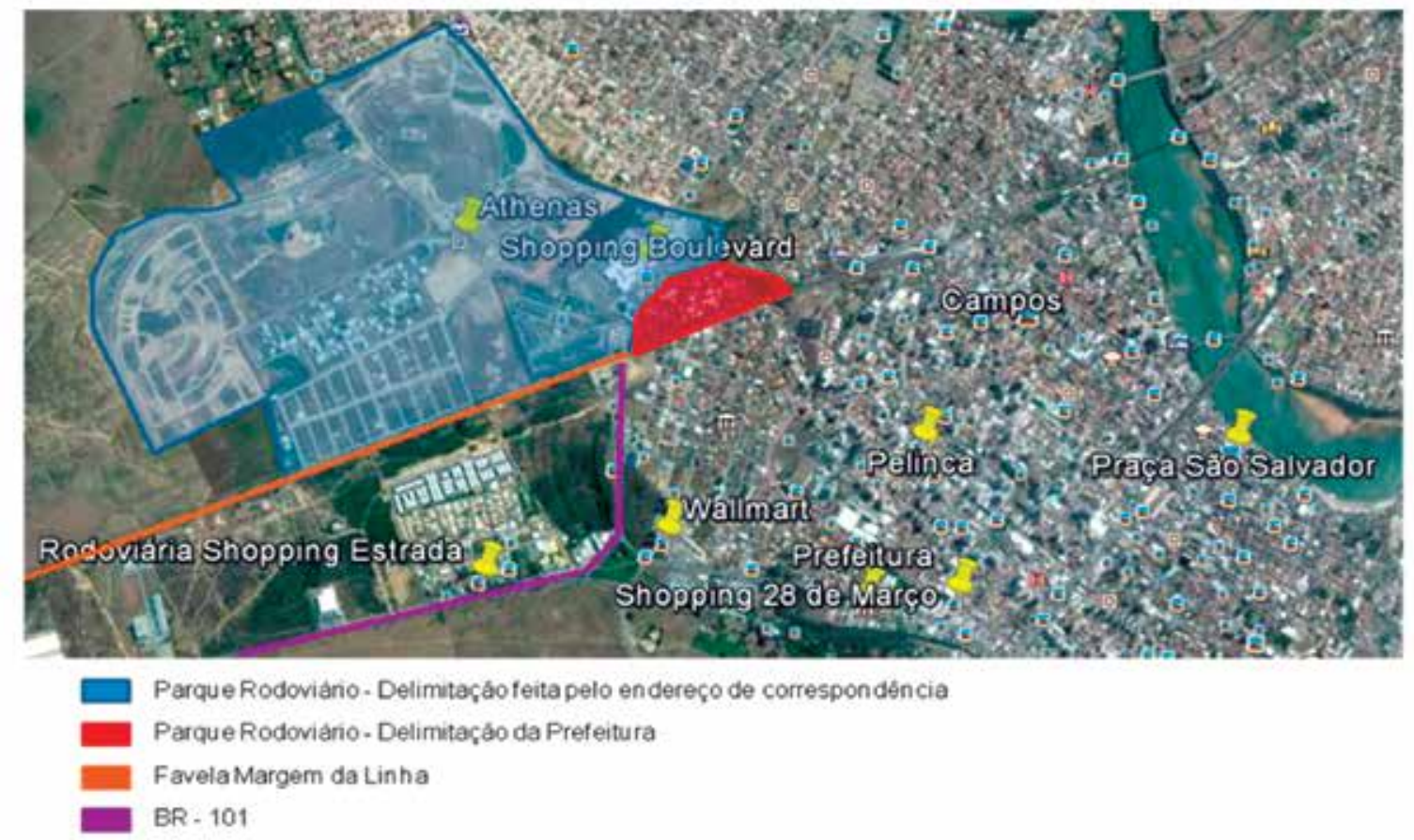

Fonte: Google Earth, adaptado por Viviane Rangel Ribeiro Manhães

Podemos observar na Figura 03, que apesar do condomínio estudado localizar-se em área periférica, essa periferia não é tão distante do novo centro que é o Bairro Pelinca. Ressaltamos, ainda, os inúmeros serviços que são oferecidos bem próximos ao condomínio.

Se por um lado, a violência, poluição, congestionamento configuram o imaginário das grandes cidades; por outro, pode-se observar que a construção de uma imagem oposta é sugerida pelos condomínios horizontais fechados: a calmaria, o silêncio, o ar puro, as ruas largas e arborizadas. A imagem vendida pelos condomínios horizontais fechados pertenceria ao ideal urbano, e por isso afirmamos assemelharem-se à imagem do paraíso terreno, de um lugar perfeito e sem problemas (IVO, 2012).

A análise das respostas dos entrevistados permitiu o delineamento das expectativas dos moradores do condomínio em duas perspectivas: 1- Qualidade de Vida: áreas verdes e de lazer; e 2- exclusivismo de classe: relações de vizinhança e status social. Um dos itens que mais se destacou nas entrevistas foi à busca pela "Qualidade de vida", que se expressa no 
anseio por áreas verdes e de lazer. Todos os moradores entrevistados apontaram como um dos principais motivos para escolha do condomínio analisado foi a existência de generosas áreas verdes e de lazer.

As falas de alguns moradores entrevistados revelam esse desejo de morar em um lugar mais calmo e tranquilo, perto da natureza, onde podem praticar hábitos esquecidos nas grandes cidades. Assim vejamos:

"O pomar do condomínio foi feito pelo meu pai. Ele adora plantar árvores frutíferas. E ele cuida delas". (Moradora 01)

"O meu marido vai ao lago pescar". (Moradora 06)

"Tem o grupo da pesca. Eu adoro pescar". (Morador 07)

Esses condomínios parecem tentar construir uma cidade ideal removendo os defeitos da cidade real indo de encontro ao entendimento de Lefebvre (2001) no qual os condomínios horizontais fechados parecem negar qualquer relação com a pluralidade, com a diversidade, com o coletivo. Vale notar que, para Lefebvre (2001), ao contrário do discurso feito pelos condomínios, a vida urbana é feita de encontros, desencontros, confrontações com aquele que é diferente, conhecimentos e reconhecimentos recíprocos dos modos de viver, dos espaços públicos e da coletividade - sendo esta modalidade de moradia o ápice do que ela conforma como "destruição da urbanidade".

A busca pela qualidade de vida materializa-se na existência de áreas verdes e de lazer dentro desses empreendimentos ao mesmo tempo, em que, revela que as estratégias do mercado coadunam com o valor dado pelos moradores entrevistados a esses fatores. Assim é que, observamos a importância dessas perspectivas nas falas dos moradores entrevistados:

"A área de lazer e o verde foram as coisas que mais chamaram minha atenção e da minha família. O lago, o parquinho, as quadras, a academia são atrativos muito importantes na hora de escolher o local para se morar. E o Athenas tem isso tudo". (Moradora 03)

"Gostei do estilo do condomínio. Da área de lazer, da área verde, do pomar, das ruas largas e arborizadas. A área de lazer parece um parque. Não tem cara de clube. Tem animais. Levo minha filha lá e ela fica desnorteada. Isso é uma delícia. Não teria isso em uma casa qualquer". (Moradora 05)

Como já mencionado anteriormente, mesmo estando localizados em área periférica da cidade, o acesso aos serviços não se configurou como empecilho ou dificuldade para os moradores. Nas entrevistas os moradores demonstraram que estão dispostos a enfrentar um trânsito bastante pesado em horário de rush, em troca de morar em um local onde a natureza está presente, justificando a preferência por este lugar ao restante da cidade, acreditam valer muito à pena morar em um lugar rodeado pela natureza, tranquilo e calmo, sem os burburinhos da cidade.

Os indicadores de qualidade de vida dos moradores do condomínio estudado refletem um estilo de vida que não está ao alcance de qualquer cidadão, - somente daqueles que podem pagar altos preços - evidenciando-se a desigualdade dos que estão fora dos muros, contribuindo para reforçar a segregação social da sociedade em que vivemos. Assim, de acordo com Medeiros (2008), o discurso da qualidade de vida como justificativa para a construção desses espaços fechados, pode encobrir uma de suas reais finalidades: construir espaços exclusivos em áreas privatizadas, que deveriam ser públicas, para aqueles que possuem condições de pagar por eles. 
Outro fator apontado pelos moradores como uma das principais justificativas por preferirem o condomínio foi morar entre pessoas da mesma classe social e profissional - o exclusivismo de classe. Por meio das entrevistas realizadas, identificamos que morar em um lugar que ofereça um "excelente convívio social" é decisivo no momento de escolher em qual condomínio morar. Vejamos:

\begin{abstract}
"Muitos vêm morar aqui por indicação, vai um indicando para o outro. Aqui tem muitos médicos que vão indicando um para o outro." (Moradora 02)

"Outra questão que influenciou a vir morar aqui é que meu marido tem amigos de profissão que moram aqui. Eles falavam assim: você tem que comprar lá. Eu acho muito importante morar em um lugar em que você sabe quem é seu vizinho, o que ele faz. Principalmente para mim, que vim de outra cidade". (Moradora)
\end{abstract}

Nas falas, restou claro, que escolher o local de moradia por amizade ou indicação é fator que demonstra seleção dos moradores, não indicando interação social entre eles. Saber quem é meu vizinho, o que ele faz, onde trabalha e sua condição social são mecanismos apenas seletivos. $E$ apesar da proximidade física entre eles, muitas vezes não há relação de vizinhança, de intimidade.

As relações sociais são estreitadas nos locais comuns ou coletivos como os parquinhos, a academia, as quadras, o lago, onde se formam grupos que interagem socialmente, podendo citar como exemplo: o grupo de pesca, o grupo das quadras, o grupo da academia, etc. Porém aqueles que não frequentam ou não participam das atividades fornecidas pelo condomínio, vivem uma vida sem intimidade, uma vida individualizada onde os sentimentos de exclusivismo e individualismo são bastante evidentes.

Chamamos atenção nas entrevistas dos moradores para o fato de que as relações sociais são dificultadas tendo em vista trabalharem fora de casa e pelo tamanho do condomínio. É uma tendência lançarem empreendimentos cada vez maiores. Em Campos dos Goytacazes, temos condomínios que vão de 14 casas até 592 lotes, o que é facilitado pela quantidade de terras localizadas nas bordas da cidade, que serviam para plantio de cana de açúcar e que foram transformadas em urbanas.

Outro fator apontado nas falas dos entrevistados é que o condomínio proporciona status social uma vez que valoriza práticas de exclusividade quanto aos espaços de lazer, as áreas verdes que circundam os condomínios, a segurança privada, as modernas tecnologias e infraestruturas, o projeto de arquitetura, transformando-os em elementos que proporcionam distinção social (DACANAL, 2005). Interessante observar, que até mesmo o portal de entrada desses condomínios corrobora para um "novo conceito de morar", onde a arquitetura é símbolo de distinção social. Os grandes portais, os suntuosos jardins e até mesmo os nomes dados às esses condomínios remetem a lugares majestosos, imponentes, o que também confere status social aos seus moradores.

Assim, podemos observar que as razões que permeiam os condomínios horizontais fechados foram modificadas no decorrer dos anos. Novas necessidades foram aparecendo. Evidentemente, não estamos afirmando que o fator segurança não seja uma razão importante quando se fala em condomínio residencial fechado. Estamos dizendo que o discurso em torno dos condomínios de alto padrão parece ter sido alterado surgindo hoje, outras necessidades, como morar mais próximo da natureza, longe do barulho e da poluição que assolam a cidade, ter serviços exclusivos como esportes e lazer, morar com pessoas que possuem o mesmo padrão social e cultural. Percebe-se que a busca por qualidade de vida está associada à ruralidade, ao bucolismo presente no campo, e essas características são elementos importantes quando se opta em morar em um condomínio fechado segundo nosso estudo de caso. 


\section{Considerações finais}

Os condomínios horizontais fechados constituem um fenômeno urbano que vem se espalhando por várias cidades brasileiras, em especial nas cidades médias. A proliferação desses condomínios horizontais fechados vem modificando a configuração espacial da cidade de Campos dos Goytacazes, levando a uma maior segregação socioespacial e fragmentação da cidade.

O estudo observou que, com a decadência do setor sucroalcooleiro na cidade de Campos a partir da década de 1980, as terras para cultivo de cana de açúcar tornaram-se ociosas ocasionando uma rápida expansão urbana em direção a estas terras, abrindo margem para especulação imobiliária, o que levou a valorização dessas terras e a transformação de antigas áreas rurais em áreas urbanas (ZACCHI, 2012). Em Campos dos Goytacazes, os condomínios fechados se expandiram sobre as antigas áreas rurais de forma dispersa e difusa.

Dentro deste contexto, verificou-se que em Campos, o poder público tem sido pouco atuante frente à expansão desse tipo de empreendimento. A malha urbana da cidade foi profundamente modificada para suportar a implantação dos condomínios sem qualquer legislação que os regularize e/ou mitigue os efeitos dos impactos espaciais e sociais acarretados por esses empreendimentos. Como esses condomínios são instalados em áreas que eram rurais e foram transformadas em urbanas, não existem leis que regulamentem essas novas áreas, colaborando para um maior espraiamento urbano e descontinuidades territoriais.

Além disto, especialmente no caso dos condomínios de médio e alto padrão, de acordo com as entrevistas realizadas, temos a configuração de um processo de "autosegregação" que dentre as diversas motivações possíveis, parece ter se modificado ao longo dos anos. A violência não apareceu nas entrevistas realizadas como principal fator de aquisição de moradia no condomínio estudado. A análise das entrevistas permitiu o delineamento das expectativas dos moradores entrevistados em duas perspectivas principais: 1- Qualidade de vida: áreas verdes e de lazer; e 2- Exclusivismo de classe: relações de vizinhança e status social. A segurança deixou de ser um elemento de primordial em nosso estudo de caso. Mesmo com oferta de modernos sistemas de segurança, guaritas e altos muros, os condomínios não podem garanti-la por completo, como afirmaram os entrevistados, reafirmando um discurso de desordem urbana, de que a "violência está em todos os lugares". 


\section{Referências bibliográficas}

ANDRADE, Luciana Teixeira de. Segregação socioespacial e vida cotidiana: o caso dos condomínios fechados. Observatório de políticas Urbanas da PUC Minas e a Pesquisa Metrópole, Desigualdades Socioespaciais e Governança Urbana, 2002.

ARRUDA, Ana Paula Serpa Nogueira de. Política habitacional e direito à cidade: a experiência do Programa "Morar Feliz" em Campos dos Goytacazes-RJ. Tese de doutorado apresentada ao Programa Pós Graduação em Sociologia Política, UENF/PGSP, 2014.

CALDEIRA, Teresa P. do Rio. Cidade de muros: crime, segregação e cidadania em São Paulo. São Paulo: Editora 34/Edusp, 2000.

CANETTIERI, Thiago. Uma nova segregação metropolitana: as periferias fractais evidências encontradas na Região Metropolitana de Belo Horizonte. R.B . Estudos Urbanos e Regionais, v.17, n.2, p.25-39, agosto 2015.

DACANAL, C. Acesso Restrito: Reflexões sobre a qualidade ambiental percebida por habitantes de condomínios horizontais. Rio Claro: UNESP-IGCE, Dissertação de Mestrado em Geografia, 2004.

D'OTTAVIANO, M.C.L. Condomínios Fechados na Região Metropolitana de são Paulo: fim do modelo centro rico versus periferia pobre? São Paulo: 2008. [Tese de Doutorado].

FISHMAN, R. Bourgeois Utopias: Visions of Suburbia in FAINSTEIN, S. e CAMPBELLS, S. Readings in Urban Theory. Oxford/Cambridge: Blackwell, 2002, p. 23-60.

IVO, Ary Brito Leal. Jardins do Éden: Salvador, uma cidade global-dual. Caderno CRH, Salvador, v. 25, n. 64, p. 131-146, jan. /abr. 2012.

KLINTOWITZ, Danielle (Org.). Royalties: recursos para políticas públicas e desenvolvimento sustentável. São Paulo: Instituto Pólis, 2016. (Caderno Temático, 2).

LEFEBVRE, Henri. O direito à cidade. São Paulo: Centauro, 2001.

MEDEIROS, Cintia Rodrigues de Oliveira. Condomínios Horizontais Fechados: segregação do espaço social. Revista Eletrônica de Administração - FACEF, vol. 11. ed. 12, janeiro/ julho, 2008.

MELGAÇO, Lucas. Securização Urbana: da psicoesfera do medo à tecnoesfera da segurança. 2010. Tese (Doutorado em Geografia) Universidade de São Paulo e Universidade de Paris 1 - Panthéon Sorbonne. 2010.

RIBEIRO, L. C. de Q. Dos cortiços aos condomínios fechados: as formas de produção da moradia na cidade do Rio de Janeiro. Rio de Janeiro: Civilização Brasileira: IPPUR, UFRJ: FASE, 1997.

SABATINI, F., CÁRCERES, G. e CERDA, J. Segregação residencial nas principais cidades chilenas: tendências das três últimas décadas e possíveis cursos de ação. In: Espaços \& Debate - Revista de Estudos Regionais e Urbanos, n 45. São Paulo: jan/jul, 2004, p. 60-74.

SANTOS, Elizete de Oliveira. Segregação ou fragmentação socioespacial? Novos padrões de estruturação das metrópoles latino-americanas. Geotextos, v. 9, n. 1, jul. 2013, p. 41-70.

ZACCHI, Raquel Callegario. O papel dos proprietários fundiários e do Estado no processo de conversão de terras rurais em urbanas e na produção de loteamentos fechados: Campos dos Goytacazes/RJ (1980-2011). Campos dos Goytacazes:UENF, 2012. [Dissertação de Mestrado]. 